\title{
Empowerment and enablement as predictors of change in health-related quality of life among patients participating in a Supported OsteoArthritis Self-Management Programme - a prospective observational study
}

Karin Sturesdotter Åkesson ( $\sim$ Karin.sturesdotter_akesson@med.lu.se )

Lund University

Anne Sundén

Lund University

kjerstin Stigmar

Lund University

Frida Eek

Lund University

Teresa Pawlikowska

RCSI University of Medicine and Health Sciences

Eva Ekvall Hansson

Lund University

\section{Research Article}

Keywords: physiotherapist, patient education, osteoarthritis, patient partner, quality of life, prediction, empowerment, enablement, primary health care

Posted Date: March 2nd, 2022

DOI: https://doi.org/10.21203/rs.3.rs-1362716/v1

License: (c) (i) This work is licensed under a Creative Commons Attribution 4.0 International License. Read Full License 


\section{Abstract}

Background: Osteoarthritis is a leading cause of disability worldwide. Current treatment supports coping strategies to improve health-related quality of life (HRQoL). The need to predict response to treatment has been raised to personalise care. This study aims to examine change in HRQoL from baseline to three and nine months follow-up after participating in a Supported OsteoArthritis Self-Management Programme (SOASP) and to examine if empowerment and/or enablement could predict change in HRQoL among patients participating in a SOASP.

Methods: Patients participating in a SOASP were recruited consecutively between April 2016 and June 2018. The EQ-5D was used to measure HRQoL, the SWE-RES-23 23 (score range 1-5) to measure empowerment and the PEI (score range 0-12) to measure enablement. The instruments were answered before (EQ-5D, SWE-RES-23) and after (EQ-5D, SWE-RES$23, \mathrm{PEI})$ the SOASP. A patient partner was engaged to enhance the patient perspective. Changes in outcome were examined with paired sample t-test and standardized effect sizes (Cohen's $d$ ). Potential predictive variables were tested with multiple linear regression analysis.

Results: In total, 143 patients participated in baseline measurement. The mean EQ-5D-5L index score increased significantly from baseline to three months corresponding to a standardised effect size (Cohen's $d$ ) of $d=.43,95 \% \mathrm{Cl}[.24$, .63] ( $n=109)$, and from baseline to nine months $d=.19,95 \% \mathrm{Cl}[.01, .37](n=119)$. The average EQ VAS score increased significantly from baseline to three months corresponding to a standardised effect size of $d=.26,95 \% \mathrm{Cl}[.07, .45]$ ( $n=109)$, and from baseline to nine months $d=.18,95 \% \mathrm{Cl}[.00, .36](n=119)$. Neither the SWE-RES-23 nor the PEI at three months follow-up or the change in the SWE-RES-23 score from baseline to three months follow-up predicted change in either EQ-5D-5L index ( $p>$.05) or the EQ VAS ( $p>$.05).

Conclusions: Health-related quality of life increased after participating in a SOASP. Empowerment and enablement as measured with the SWE-RES-23 and the PEI respectively could not predict change in HRQoL among patients participating in a SOASP.

Trial registration: ClinicalTrials.gov. Identification number: NCT 02974036. First registration 28/11/2016, retrospectively registered.

\section{Background}

Osteoarthritis (OA) is one of the most disabling diseases among older adults [1]. According to worldwide estimates, about $9.6 \%$ of men and $18.0 \%$ of women over the age of 60 years have symptomatic OA [1]. The demands on the health care system will increase since OA prevalence is increasing due to population ageing and an increase in risk factors for developing OA such as obesity [2].

In Sweden, national guidelines are available for a number of health conditions to support decision makers in allocating resources within the health care system $[3,4]$. The purpose of guidelines is to ensure quality of health care $[3,4]$. The Swedish national guidelines for OA recommend a structured care approach where early diagnosis based on patient history and clinical examination is emphasised [3]. All OA patients should be offered first line treatment i.e., patient education, exercise, coping strategies and weight loss if needed [3]. First line treatment for OA is often provided by a physiotherapist (PT) through a Supported OsteoArthritis Self-Management Programme (SOASP) in primary health care (PHC) in Sweden [5]. The SOASP combines patient education with exercise and aims to support patients to cope with their disease, improve health-related quality of life (HRQoL), increase physical activity level, and reduce healthcare consumption and sick leave due to OA $[5,6]$.

In Sweden, there is a unique opportunity to evaluate the SOASP through a national quality register called Better Management for Patients with OA, BOA [6]. In the past few years, the estimated coverage ratio for the register has been 
somewhere between $60-70 \%$ [7]. The BOA register contains data on for example physical activity level, pain and HRQoL collected through Patient Reported Outcome Measures (PROMs) [6]. However, whether the patients report to be able to cope with their disease after participating in the SOASP is not, to our knowledge, routinely evaluated to date.

Empowerment has been described as a process to gain control over decisions that affects their health and personal life [8]. Patient enablement has to do with a person's ability to understand and cope with their disease after a consultation in health care $[9,10]$. The concepts of empowerment and enablement are closely related [11-13]. Empowerment can be measured with the Swedish Disease Empowerment Scale (SWE-RES-23) [14] and patient enablement with the Patient Enablement Instrument (PEI) $[9,10,15]$. Both the SWE-RES-23 and the PEI can be used to evaluate patient's ability to cope with their disease after participating in a SOASP (Sturesdotter Åkesson et al. Enablement and empowerment among patients participating in a Supported OsteoArthritis Self-Management Programme - A prospective observational study, in manuscript, unpublished).

Studies have shown an association between empowerment and HRQoL [16] in different contexts and in different diseases like cancer [17], rheumatoid arthritis [18, 19] and in OA patients after total hip or total knee arthroplasty [16]. For enablement, studies have shown an association between enablement and self-reported health [20-22] and a correlation between enablement and change in asthma-related quality of life [23]. To the best of our knowledge, there is a research gap regarding the association between empowerment, enablement and HRQoL after participating in a SOASP.

As the population ages and OA prevalence is expected to increase continuously, the burden of OA will increase accordingly [1]. Consequently, patients suffering from chronic diseases such as OA will have to be able to take care of themselves to a greater extent in the coming years [24]. Resources in health care are limited and it is vital that they are used effectively and for those who need it the most $[3,4]$. Therefore, it is crucial to be able to identify patients with the greatest need for additional support, medical care and treatment [25] and the need to predict response to treatment has been raised to tailor treatment and personalise care $[26,27]$. The aim of our study was to examine change in healthrelated quality of life from baseline to three and nine months follow-up after participating in a Supported OsteoArthritis Self- Management Programme. Furthermore, to examine if empowerment and/or enablement could predict change in health-related quality of life among patients participating in a Supported OsteoArthritis Self-Management Programme.

\section{Methods}

\section{Design and setting}

We used data from patients with OA of the hip and/or knee participating in a SOASP in PHC to conduct this prospective observational cohort study. The study was conducted in compliance with the Declaration of Helsinki [28] and was approved by the Regional Ethical Review Board in Lund, Sweden (2015/918). The Strengthening the Reporting of Observational Studies in Epidemiology (STROBE) checklist was used as guidance when reporting this study [29] (Appendix 1). This study was registered with ClinicalTrials.gov. Identification number: NCT 02974036 . Retrospectively registered 28/11/2016.

\section{Participants}

Inclusion criteria were patients with OA of the hip and/or knee, understanding Swedish and participating in a SOASP. There were no other exclusion criteria. Patients were recruited consecutively between April 2016 and June 2018 and consented by the PT responsible for the SOASP at the PHC centre. All participants were given written and verbal information about the study and gave written informed consent for study participation prior to the start of the study. We 
included patients that had paired data, i.e., prior to the participation in the SOASP at baseline and at follow-up at nine months on HRQoL $(n=119)$, in the analysis.

\section{Data collection}

Data was collected from two regions in Sweden: Region Skåne (five PHC centres, $n=87$ ) and Region Blekinge (two PHC centres, $n=56$ ) where the SOASP was offered. The participants answered the EQ-5D and the SWE-RES-23 prior to the participation in the SOASP at baseline and at follow-up at three months. The EQ-5D was also answered at follow-up at nine months and the PEI was solely answered at three months follow-up. Data was collected by the PT responsible for the SOASP at the PHC centre at baseline and at three months follow-up and by the first author at nine months follow-up through a postal questionnaire. Flowchart for the data collection for analysis in the study is presented in Fig. 1 (Fig. 1).

\section{Outcome measure}

All study data were based on PROMs. Health-related quality of life (HRQoL) was measured with the EQ-5D, which is a generic non-disease specific PROM [30-33] used frequently in OA research [34, 35]. The EQ-5D consists of two parts: the descriptive part (EQ-5D-5L) and the visual analogue scale (EQ VAS) [33]. The descriptive part consists of five dimensions: mobility, self-care, usual activities, pain/discomfort, and anxiety/depression [32,33]. For each dimension there are five alternative answers referring to level of problems that correspond to a number $(1=$ no, $2=$ slight, $3=$ moderate, $4=$ severe, and 5 = extreme/unable to) [32,33]. Each number can be combined into a five-digit number describing 3125 unique health profiles [32,33]. The health profiles can be represented by an index value where lower values reflect lower HRQoL and higher values reflect higher HRQoL [36]. On the EQ VAS, the patients report their self-rated health on a vertical visual analogue scale ranging from 100 (best imaginable health) to 0 (worst imaginable health) [33]. The EQ-5D has been translated to Swedish [33] and has shown sufficient reliability [34] and validity [37] for use in relation to OA. The Swedish tariff was used in our study [33].

Empowerment was measured with the Swedish Rheumatic Disease Empowerment Scale (SWE-RES-23) (Appendix 2) [14]. The SWE-RES-23 consist of 23 questions with five alternative answers ranging from strongly disagree (scored 1) to strongly agree (scored 5) which is summarised as a total average score between 1 to 5 points where a higher score indicates higher empowerment [14].

Enablement was measured with the Patient Enablement Instrument (PEI) (Appendix 3) $[9,10,15]$ that measures a patient 's perceived ability to understand and cope with their disease and is answered after a consultation $[9,10,15]$. The PEI consists of six questions with four alternative answers: much better (scored 2), better (scored 1), same or less (scored 0), not applicable (scored 0 ), resulting in a possible total consultation score between 0 to $12[9,10,15]$ where a higher score indicates higher enablement $[9,10,15]$. The basis for the development of the PEI was the idea that how the patient feels

and perceives life is important when predicting outcome $[15,38]$. The PEI and the SWE-RES-23 have been translated to Swedish and tested for reliability $[14,39]$ and for validity $[14,40]$. The measurements used in this study (the EQ-5D-5L, the SWE-RES-23 and the PEI) have been described more in detail elsewhere [9, 10, 14, 15, 32, 33] (Sturesdotter Åkesson et al. Enablement and empowerment among patients participating in a Supported OsteoArthritis Self-Management Programme - A prospective observational study, in manuscript, unpublished).

\section{Patient partner}

We engaged a patient partner (PP) from the Swedish Rheumatism Association to enhance the patient perspective. The PP collaborated actively from the planning of the study throughout the research process and contributed with lived experience of OA, experience of participating in SOASPs and of patient expertise in relation to the study. In the planning 
phase of the study, the PP reviewed and commented on the PROMs and data collection methods to ensure that the chosen method was appropriate for OA patients. Moreover, the PP was consulted about the readability of the written patient information and consent form. We discussed the study with the PP during the data collection and the PP was consulted when analysing the results to see if the PP's interpretation was the same as that of the research team. When planning the study, we met with the PP face to face at a network event and after that we kept contact digitally and through email. We used the Guidance for Reporting Involvement of Patients and the Public (GRIPP2-SF) checklist [41, 42] as a guide when reporting the PP's involvement in our study (Appendix 4).

\section{Statistical analysis}

Descriptive statistics are presented as frequencies and percentages for categorical data and as means and standard deviations for numerical data. Change in EQ-5D-5L from baseline to three and nine months respectively was analysed with paired samples t-test. Standardised effect sizes (Cohen's $d, \mathrm{Cl} 95 \%$ ) were analysed [43] and categorised as small (.2), medium (.5) or large (.8) [43].

A multiple linear regression was performed to assess if the SWE-RES-23 at three months follow-up and change in the SWE-RES-23 score from baseline to three months follow-up and the PEI, predicted change in HRQoL (EQ-5D-5L index and EQ VAS respectively) from baseline to nine months follow-up after a SOASP. Preliminary analyses were performed to ensure there was no violation of the assumption of normality, linearity, and multicollinearity. The total score of the SWERES-23 and the PEl at three months follow up and the change in in the SWE-RES-23 score during the SOASP (from baseline to three months follow-up) were entered as independent variables in model 1. To control for the potential influence of age, gender and the EQ-5D score at baseline (for EQ-5D-5L index and EQ VAS respectively) these variables were entered in model 2.

A sample size calculation for a primary study using the same study sample (Sturesdotter Åkesson et al. Enablement and empowerment among patients participating in a Supported OsteoArthritis Self-Management Programme - A prospective observational study, in manuscript, unpublished) showed that to be able to detect an association corresponding to a correlation coefficient between .3 to 0.5 with a power of .80 at a chosen significance level of $.05,110$ participants were needed. The sample size calculation for the primary study was performed with respect to multiple statistical analyses being planned on the same study sample in the present subsequent study. SAS Enterprise Guide 6.1 for Windows (SAS Institute Inc., Cary, NC, USA) was used for sample size calculation. To compensate for potential missing data, data from 143 participants were collected. No imputation was made for missing values [44]. All statistical analysis was performed with IBM SPSS Statistics 27.

\section{Results}

Baseline PROMs were answered by 143 patients. Demographic data for the study sample with paired data i.e., prior to the participation in the SOASP at baseline and at follow-up at nine months on HRQoL $(n=119)$ are presented in Table 1. 
Table 1

Sample characteristics for the study sample with paired data on health-related quality of life.

\begin{tabular}{|ll|}
\hline & Study sample $(\boldsymbol{n}=119)$ \\
\hline Gender \% $(n)$ & $23(27)$ \\
\hline Men & $77(92)$ \\
\hline Age (years) & \\
\hline mean (SD) & $66.4(8.7)$ \\
\hline min-max & $40-90$ \\
\hline Most affected joint \% $(n)$ & \\
\hline knee & $72.3(86)$ \\
\hline hip & $25.2(30)$ \\
\hline hand & $2.5(3)$ \\
\hline missing data & \\
\hline BMI mean (SD) & $28.7(6.4)$ \\
\hline
\end{tabular}

The highest average value for the EQ-5D-5L index and the EQ VAS was observed at three months follow-up (Table 2). 
Table 2

Descriptive data on health-related quality of life measured with the EQ-5D-5L index and the EQ VAS at baseline, 3 and 9 months follow-up and the mean change in the EQ-5D-5L index and the EQ VAS from baseline to 3 and 9 months followup.

\begin{tabular}{|c|c|c|c|c|c|c|c|c|c|c|c|}
\hline & $\begin{array}{l}\text { Baseline } \\
(\mathrm{n}= \\
119)\end{array}$ & $\begin{array}{l}3 \\
\text { months } \\
\text { follow- } \\
\text { up }(n= \\
109)\end{array}$ & $\begin{array}{l}9 \\
\text { months } \\
\text { follow- } \\
\text { up }(n= \\
119)\end{array}$ & $\begin{array}{l}\text { Mean } \\
\text { change } \\
\text { baseline } \\
\text { to } 3 \\
\text { months } \\
(n= \\
109)\end{array}$ & $\begin{array}{l}95 \% \\
\mathrm{Cl}^{\mathrm{c}}\end{array}$ & $p$-value ${ }^{d}$ & $d^{e}$ & $\begin{array}{l}\text { Mean } \\
\text { change } \\
\text { baseline } \\
\text { to } 9 \\
\text { months } \\
(n= \\
119)\end{array}$ & $\begin{array}{l}95 \% \\
\mathrm{Cl}^{\mathrm{C}}\end{array}$ & $p$-value ${ }^{d}$ & $d^{e}$ \\
\hline \multicolumn{12}{|c|}{$\begin{array}{l}\text { Mean } \\
\text { (SD) }\end{array}$} \\
\hline $\begin{array}{l}\text { EQ- } \\
5 D^{-} \\
5 L^{a}\end{array}$ & $\begin{array}{l}.810 \\
(.128)\end{array}$ & $\begin{array}{l}.852 \\
(.118)\end{array}$ & $\begin{array}{l}.832 \\
(.127)\end{array}$ & .040 & $\begin{array}{l}.02 \\
.06\end{array}$ & $\leq .001$ & .09 & .022 & $\begin{array}{l}.00 \\
.04\end{array}$ & .04 & .11 \\
\hline $\begin{array}{l}\text { EQ } \\
\text { VAS }^{b}\end{array}$ & $\begin{array}{l}68.9 \\
(19.2)\end{array}$ & $\begin{array}{l}72.7 \\
(19.4)\end{array}$ & $\begin{array}{l}71.9 \\
(17.2)\end{array}$ & 3.5 & $\begin{array}{l}.97 \\
6.1\end{array}$ & .01 & 13.5 & 3.0 & $\begin{array}{l}.04 \\
6.0\end{array}$ & .05 & 16.7 \\
\hline \multicolumn{12}{|c|}{ a total score range $0-1$} \\
\hline \multicolumn{12}{|c|}{$\mathrm{b}$ total score range $0-100$} \\
\hline \multicolumn{12}{|c|}{${ }^{\mathrm{C}} \mathrm{Cl}=$ confidence interval for mean change baseline to 3 and 9 months respectively } \\
\hline \multicolumn{12}{|c|}{$\begin{array}{l}\text { d significance level } p<.05, p \text {-value for mean change baseline to } 3 \text { and } 9 \text { months respectively analysed with paired } \\
\text { sample t-test }\end{array}$} \\
\hline \multicolumn{12}{|c|}{ e $d=$ Cohen's d (standardised effect size) } \\
\hline
\end{tabular}

The mean EQ-5D-5L index score increased significantly from baseline to three months corresponding to a standardised effect size (Cohen's $d$ ) of $d=.43,95 \% \mathrm{Cl}[.24, .63](n=109)$, and from baseline to nine months $d=.19,95 \% \mathrm{Cl}[.01, .37]$ ( $n$ =119). The average EQ VAS score increased significantly from baseline to three months corresponding to a standardised effect size of $d=.26,95 \% \mathrm{Cl}[.07, .45](n=109)$, and from baseline to nine months $d=.18,95 \% \mathrm{Cl}[.00, .36](n=119)$.

The self-reported average outcome for the SWE-RES-23 was 3.7 (SD .6) at baseline $(n=118)$ and 3.9 (SD .5) at three months follow-up $(n=105)$. For the PEl the average outcome was 6 (SD 3.2) at three months follow-up $(n=105)$. Neither the SWE-RES-23 nor the PEI at three months follow-up or the change in the SWE-RES-23 score from baseline to three months follow-up predicted change in either EQ-5D-5L index $(p>.05)$ or the EQ VAS ( $>.05)$, and together explained $6.8 \%$ (EQ-5D-5L index) and 2.9\% (EQ VAS) of the variation. When age, gender and EQ-5D baseline values were added, the models explained $34.4 \%$ (EQ-5D-5L index) and 42\% (EQ VAS) of the variation, with baseline EQ-5D as the main significant predictor (Table 3, Table 4). Also, the PEI was significantly associated with change in EQ VAS $(\mathrm{B}=1.26,95 \% \mathrm{Cl}[.25,2.28]$ (Table 4, model 2). 
Table 3

Multiple linear regression analysis for variables predicting change in health-related quality of life measured with EQ-5D-5L index from baseline to 9 months follow-up.

\begin{tabular}{|c|c|c|c|c|c|c|c|c|}
\hline \multirow{2}{*}{ Variables } & \multicolumn{4}{|c|}{ Model 1} & \multicolumn{4}{|c|}{ Model 2} \\
\hline & B & $95 \% \mathrm{Cl}$ & B & $\begin{array}{l}p- \\
\text { value }\end{array}$ & B & $95 \% \mathrm{Cl}$ & ß & $\begin{array}{l}p- \\
\text { value }^{e}\end{array}$ \\
\hline $\mathrm{PEl}^{\mathrm{a}}$ at 3 months $(\mathrm{n}=105)$ & .01 & $\begin{array}{l}-.00 \\
.02\end{array}$ & .18 & .128 & .01 & $-.00, .01$ & .16 & .111 \\
\hline SWE-RES- $23^{\text {b }}$ at 3 months $(n=105)$ & .00 & $\begin{array}{l}-.05 \\
.06\end{array}$ & .01 & .953 & .05 & $-.00, .10$ & .21 & .054 \\
\hline $\begin{array}{l}\text { Change in SWE-RES-23 } \text { score }^{\mathrm{C}}(= \\
104)\end{array}$ & .03 & $\begin{array}{l}-.01 \\
.08\end{array}$ & .15 & .157 & .02 & $-.02, .06$ & .10 & .262 \\
\hline $\begin{array}{l}\text { EQ-5D-5L }{ }^{d} \text { index at baseline }(n= \\
119)\end{array}$ & & & & & -.50 & $\begin{array}{l}-.67 \\
-.33\end{array}$ & -.55 & $\leq .001$ \\
\hline Age $(n=119)$ & & & & & .00 & $-.00, .02$ & -.02 & .852 \\
\hline Gender $(n=119)$ & & & & & -.01 & $-.06, .02$ & -.05 & .561 \\
\hline $\mathrm{R}^{2}$ & .07 & & & & .34 & & & \\
\hline Adjusted $\mathrm{R}^{2}$ & .04 & & & & .30 & & & \\
\hline \multicolumn{9}{|c|}{ a PEl: Patient Enablement Instrument, measuring enablement } \\
\hline \multicolumn{9}{|c|}{${ }^{\mathrm{c}}$ Change in the SWE-RES-23 score during the SOASP (i.e., from baseline to 3 months follow-up) } \\
\hline \multicolumn{9}{|c|}{${ }^{d}$ EQ-5D-5L: descriptive part of EQ-5D, measuring health-related quality of life } \\
\hline e significance level $p<.05$ & & & & & & & & \\
\hline
\end{tabular}


Table 4

Multiple linear regression analysis for variables predicting change in health-related quality of life measured with EQ VAS from baseline to 9 months follow-up.

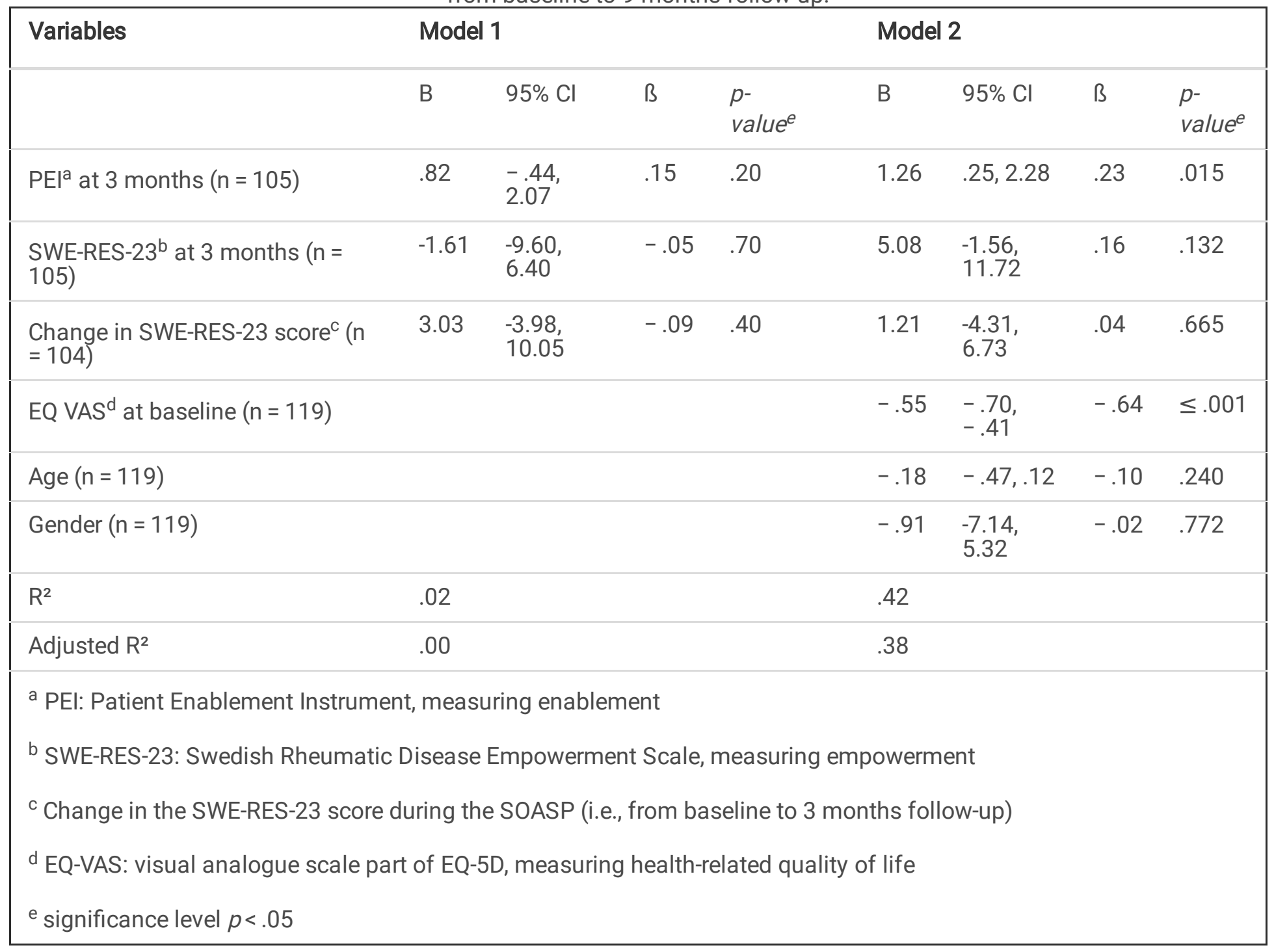

\section{Discussion}

In our study, the patients reported relatively high HRQoL, as measured with the EQ-5D, at baseline and at follow-up at three and nine months. The change in HRQoL between baseline and three and nine months respectively, corresponded to a statistically significant but small effect size regarding both the EQ-5D-5L index and the EQ VAS. To the best of our knowledge, this is the first study to examine the association between empowerment, enablement and change in HRQoL among patients participating in a SOASP. We found that empowerment and enablement did not predict change in HRQoL in this context.

The aims of the SOASP are to empower and enable OA patients to better cope with their disease and to increase HRQoL $[5,6]$. The patients in our study reported relatively high HRQoL already at baseline indicating that the patients were doing rather well at time for inclusion in our study and therefore a ceiling effect might impact further increase in HRQoL. Even so, HRQoL increased somewhat at three months and was still higher at nine months follow-up than at baseline. This outcome pattern of self-reporting HRQoL after participating in a SOASP is in line with previous reports [7,45] and is promising since it indicates that the aim of the SOASP to increase HRQoL is somewhat achieved. However, the effect size regarding HRQoL was small which might not be surprising given the high baseline values. 
Empowerment and enablement at three months follow-up and change in empowerment from baseline to three months could not predict a change in HRQoL from baseline to nine months follow-up in this context. The baseline values for the EQ-5D were entered in the adjusted models since these might have a confounding effect. No clear confounding effect was shown, but the baseline levels turned out to be the strongest independent predictor of the change in outcome, with a negative association which can at least partly be explained by the regression to the mean phenomena. Patients selfreporting lower values on the EQ-5D at baseline might have more potential to increase in HRQoL from baseline to nine months follow-up. On the other hand, patients self-reporting higher values on the EQ-5D already at baseline might increase less since there is less room for improvement. Health-related quality of life (HRQoL) vary for men and women [45-47] and in different ages $[46,48]$ so for that reason age and gender were entered as covariates. However, in this context, age and gender were not associated with the change in HRQoL.

Patients that self-report lower levels of HRQoL might have most to gain from participating in an empowering and enabling intervention like a SOASP. Thus, the results of our study might have been different with such an OA population i.e., those with lower levels of HRQoL. This idea was acknowledged by our PP who also highlighted that patients that choose to seek care and to participate in a SOASP might be more optimistic, able and empowered than the average patient and that a certain amount of empowerment and enablement is needed to be able to take care of oneself and actively seek health care. More research is needed when it comes to empowerment, enablement and HRQoL in relation to SOASP. In our study, the patients reported relatively high values on empowerment and enablement $[9,18]$ at all measuring points. It is a challenge to reach patients who might benefit most from participating in a SOASP and to include them in research. More effort should be made to reach out to OA patients and to make treatment more appealing and perhaps more tailored. A closer cooperation with patient partners and OA patient organisations might be part of a solution of reaching more OA patients and in developing OA treatment.

The SWE-RES-23 was developed in 2012 [14] and is a relatively new instrument that has not been widely used in studies yet. The approach in published studies $[18,19]$ differ from ours so the possibility for comparisons with other studies is limited. Therefore, the current study might contribute with scientific basis for future studies.

The PEl is considered to be the "gold standard" when measuring enablement [49]. In our study, enablement was measured at three months follow-up. The PEI was developed to be answered after a consultation $[9,15]$ and patients selfreport their perceived change in enablement compared to before the consultation $[9,50]$. Therefore, as there is no baseline measure [50] it is thus not possible to compute a change in enablement between baseline and three months follow-up. Again, the PEl value reported in our study is moderate to high and this tends to support the argument that the participants started with relatively good understanding and coping ability perhaps motivating them to enter the SOAPS. There is also a risk of recall bias as the PEI was answered at three months since patients might not accurately recall their baseline status [50] and this has to be taken in consideration when interpreting the results. Subgroup analysis was not possible in our study, but the PEl has shown to differ by age and gender [15].

When taking part of the results from this study, the PP noted that patients seem to feel better during the SOASP and as long as they were in contact with the PT since they report higher HRQoL at that point (i.e., from baseline to three months follow-up). Moreover, the PP reported that patients contact the Swedish Rheumatism Association and want to continue to exercise in health care since they feel safe there. Hence, there seems to be a gap between what patients ask for and what health care can offer. It is a challenge for health care to meet these needs as well as allocate resources as fairly as possible.

As the PP highlighted, all of this tends to support the notion that the patients included in our study were motivated enough to contact PHC, to participate in the SOASP and in our study. Therefore, they might not be representative to the average OA patient in Sweden. The idea that the SOASP does not reach out to all OA patients has been raised [45, 51]. The reasons for why OA patients do not participate in a SOASP might vary from patients not being offered to participate 
or patients not wanting to participate [52]. Moreover, the PP highlighted that OA patients with comorbidities might not be participating in the SOASP due to other diseases having to be prioritised and fatigue might also be a hindering factor. A recently published study has shown that comorbidities were more common among OA patients than among the general population [53].

In future studies, an even further longitudinal perspective than in the present study, on all the PROMs prior to, and after the SOASP should be taken to study the association between patient empowerment, enablement and HRQoL. A larger longitudinal sample would also permit subgroup analysis regarding gender, level of education, socioeconomic status, most affected OA joint and body mass index.

\section{Strengths and weaknesses}

A strength with the study was that data was collected in clinical practice which supports external validity. Another strength was that the response rate was high, and the amount of missing data was minimal. This might be explained by the fact that data collection was performed by PTs' used to collecting PROMs linked to the SOASP. A PP was involved in the whole research process adding deeper meaning and relevance to the study. In the planning phase, the PP affirmed the importance of the research question, reviewed the questionnaires used in the study and commented on the proposed data collection methods. When analysing and interpreting data, the PP was consulted to see if she interpreted the results in the same way as the research team. We believe that our study became more patient-centered since we involved a PP who added valuable feedback and advice in all stages of the study process. In addition, the subgroup of self-reporting low values on any of the PROMs in our study sample was small.

The observational design, and lack of control group means that no casual inferences can be made.

It is also important to bear in mind when interpreting the results of our study that only Swedish speaking patients were included in the study making the sample rather homogenous and selected which is a limitation. In addition, to date it is not known how long achieved level of HRQoL, empowerment and/or enablement lasts. Therefore, the timepoint for measuring the PROMs might matter for the results. Moreover, the PEI was only measured at a single timepoint, and repeated measuring points might provide an advantage over single timepoint measurement regarding prediction through the ability to capture change over time and less sensitivity to measurement error [54]. Hence, with additional repeated measures in the present study, the results of the predictive analyses might have been different. As is common in such "in vivo" clinical studies we do not have information regarding the reasons for patients not participating in the study.

\section{Implications}

In contemporary practice patients included in a SOASP might not be representative of the average OA patient and therefore more effort should be made to reach out to struggling OA patients who may be less motivated and especially in need of support. More research is needed to identify OA patients with greatest need for additional support and to find outcome measures to predict outcome measures for OA treatment.

\section{Conclusions}

The results of our study showed increasing HRQoL for patients with OA after participating in a SOASP. Moreover, that empowerment and enablement as measured with the SWE-RES-23 and the PEI respectively could not predict change in HRQoL among patients participating in a SOASP.

\section{List Of Abbrevations}


OA: Osteoarthritis

PT: Physiotherapist

SOASP: Supported OsteoArthritis Self-Management Programme

PHC: Primary Health Care

HRQoL: Health-Related Quality of Life

BOA: Better Management of patients with OsteoArthritis

PROM: Patient Reported Outcome Measure

SWE-RES-23: Swedish Rheumatic Disease Empowerment Scale

PEl: Patient Enablement Instrument

EQ-5D: health-related quality of life measurement (EQ-5D-5L and EQ VAS)

PP: Patient Partner

\section{Declarations}

\section{Ethics approval and consent to participate}

The study was conducted in accordance with the Declaration of Helsinki [28]. The study was approved by the Regional Ethical Review Board in Lund, Sweden (2015/918). Written informed consent was obtained from all patients before participating in the study.

\section{Consent for publication}

Not applicable.

\section{Availability of data and materials}

The dataset generated and analysed during the current study are not publicly available due to the ethics approval and Swedish law (but are available from the corresponding author on reasonable request).

\section{Competing interests}

The authors declare that they have no competing interests.

\section{Funding}

This study was supported by the Swedish Rheumatism Fund, the Stig Thunes Fund and the Greta and Johan Kocks's Foundation. The funding bodies did not take any part in the design of the study and collection, analysis, and interpretation of data and in writing the manuscript. 


\section{Authors' contributions}

KSÅ led the conception of the study, conducted the information letter, collected and analysed the data, and wrote the manuscript. All authors (KSÅ, AS, KS, EK, TP and EEH) were involved in planning the study, discussing the results and the conclusion. All authors (KSÅ, AS, KS, EK, TP and EEH) revised the manuscript critically for important intellectual content, read and approved the final manuscript.

\section{Acknowledgements}

We gratefully acknowledge all participating physiotherapists and patients involved in the study. We also acknowledge our participating patient partner for valuable support and input in the process of the study.

\section{References}

1. Wittenauer R SL, Aden K. Background Paper 6.12 Osteoarthritis. Internet. World Health Organization 2013.

2. United Nations Department of Economic Social Affairs Population Division. World population to 2300. New York: United Nations; 2004.

3. Socialstyrelsen. Nationella riktlinjer för rörelseorganens sjukdomar. Reumatoid artrit, axial spondylartrit, psoriasisartrit, artros och osteoporos. Stockholm: Socialstyrelsen; 2021.

4. National Board of Health and Welfare. National guidelines: what are they? : National Board of Health and Welfare; 2015.

5. Thorstensson CA, Garellick G, Rystedt H, Dahlberg LE. Better Management of Patients with Osteoarthritis: Development and Nationwide Implementation of an Evidence-Based Supported Osteoarthritis Self-Management Programme. Musculoskeletal Care. 2015;13(2):67-75.

6. Better Management for patients with OsteoArthritis. Better Management for patients with OsteoArthritis [Internet\} Gothenburg: Better Management for patients with OsteoArthritis; 2021 [updated 2021; cited 2022 January 10]. Available from: https://boa.registercentrum.se/.

7. Bättre Omhändertagande Av Patienter med Artros. BOA Årsrapport. BOA Bättre Omhändertagande av patienter med Artros.[Internet\} 2020. . Gothenburg; 2021.

8. Health promotion glossary. [Webpage]. WHO; [cited 2022 January 5]. Available from: https://www.who.int/healthpromotion/about/HPR\%20Glossary\%201998.pdf.

9. Howie JG, Heaney DJ, Maxwell M. Measuring quality in general practice. Pilot study of a needs, process and outcome measure. Occas Pap R Coll Gen Pract. 1997(75):i-xii, 1-32.

10. Howie JG, Heaney DJ, Maxwell M, Walker JJ. A comparison of a Patient Enablement Instrument (PEI) against two established satisfaction scales as an outcome measure of primary care consultations. Fam Pract. 1998;15(2):16571.

11. Hudon C, St-Cyr Tribble D, Bravo G, Poitras ME. Enablement in health care context: a concept analysis. J Eval Clin Pract. 2011;17(1):143-9.

12. Fumagalli LP, Radaelli G, Lettieri E, Bertele P, Masella C. Patient Empowerment and its neighbours: clarifying the boundaries and their mutual relationships. Health policy (Amsterdam, Netherlands). 2015;119(3):384-94.

13. Pekonen A, Eloranta S, Stolt M, Virolainen P, Leino-Kilpi H. Measuring patient empowerment - A systematic review. Patient education and counseling. 2020;103(4):777-87.

14. Arvidsson S, Bergman S, Arvidsson B, Fridlund B, Tingstrom P. Psychometric properties of the Swedish Rheumatic Disease Empowerment Scale, SWE-RES-23. Musculoskeletal Care. 2012;10(2):101-9. 
15. Howie JG, Heaney DJ, Maxwell M, Walker JJ, Freeman GK, Rai H. Quality at general practice consultations: cross sectional survey. BMJ (Clinical research ed). 1999;319(7212):738-43.

16. Koekenbier K, Leino-Kilpi H, Cabrera E, Istomina N, Johansson Stark $\AA$, Katajisto J, et al. Empowering knowledge and its connection to health-related quality of life: A cross-cultural study: A concise and informative title: Empowering knowledge and its connection to health-related quality of life. Appl Nurs Res. 2016;29:211-6.

17. Kaal SEJ, Husson O, van Duivenboden S, Jansen R, Manten-Horst E, Servaes P, et al.Empowerment in adolescents and young adults with cancer: Relationship with health-related quality of life. Cancer. 2017;123(20):4039-47.

18. Larsson I, Bremander A, Andersson M. Patient Empowerment and Associations with Disease Activity and PainRelated and Lifestyle Factors in Patients With Rheumatoid Arthritis. ACR Open Rheumatol. 2021.

19. Arvidsson S, Bergman S, Arvidsson B, Fridlund B, Tingstrom P. Effects of a self-care promoting problem-based learning programme in people with rheumatic diseases: a randomized controlled study. Journal of advanced nursing. 2013;69(7):1500-14.

20. Foley MJ. Enablement of older adults with chronic disease attending an ambulatory care centre. Dissertation on the Internet: University College Cork; 2020.

21. Ozvacić Adzić Z, Katić M, Kern J, Lazić D, Cerovecki Nekić V, Soldo D. Patient, physician, and practice characteristics related to patient enablement in general practice in Croatia: cross-sectional survey study. Croat Med J. 2008;49(6):813-23.

22. Simmons TA, Winefield HR. Predictors of Patient Enablement: The Role of Doctors' Helpgiving Style, Patient and Visit Characteristics. Australian Journal of Primary Health. 2002;8(3):39-46.

23. Haughney J, Cotton P, Rosen JP, Rosen JP, Morrison K, Price D. The use of a modification of the Patient Enablement Instrument in asthma. Prim Care Respir J. 2007;16(2):89-92.

24. World Health Organization. Noncommunicable Diseases and Mental Health Cluster. (2002). Innovative Care for Chronic Conditions: Building Blocks for Action: global report. Geneva: World Health Organization; 2002. Report No.: 92415901739789241590174 Contract No.: WHO/MNC/CCH/02.01.

25. Socialdepartementet. God och nära vård: en primärvårdsreform: delbetänkande av utredningen Samordnad utveckling för god och nära vård.Stockholm: Norstedts Juridik; 2018.

26. Xiong Y, Zeng C, Doherty M, Persson MSM, Wei J, van Middelkoop M, et al. Identifying predictors of response to oral non-steroidal anti-inflammatory drugs and paracetamol in osteoarthritis: a hypothesis-driven protocol for an OA Trial Bank individual participant data meta-analysis. BMJ open. 2021;11(8):e048652.

27. Hunter DJ, Bierma-Zeinstra S. Osteoarthritis. Lancet (London, England). 2019;393(10182):1745-59.

28. Association WM. World Medical Association Declaration of Helsinki: Ethical Principles for Medical Research Involving Human Subjects. JAMA. 2013;310(20):2191-4.

29. von Elm E, Altman DG, Egger M, Pocock SJ, Gøtzsche PC, Vandenbroucke JP. The Strengthening the Reporting of Observational Studies in Epidemiology (STROBE) statement: guidelines for reporting observational studies. PLoS Med. 2007;4(10):e296.

30. EuroQol G. EuroQol-a new facility for the measurement of health-related quality of life. Health policy (Amsterdam, Netherlands). 1990;16(3):199-208.

31. Brooks R. EuroQol: the current state of play. Health policy (Amsterdam, Netherlands). 1996;37(1):53-72.

32. Herdman M, Gudex C, Lloyd A, Janssen M, Kind P, Parkin D, et al. Development and preliminary testing of the new five-level version of EQ-5D (EQ-5D-5L). Qual Life Res. 2011;20(10):1727-36.

33. Burström K, Teni FS, Gerdtham UG, Leidl R, Helgesson G, Rolfson O, et al. Experience-Based Swedish TTO and VAS Value Sets for EQ-5D-5L Health States. Pharmacoeconomics. 2020;38(8):839-56. 
34. Fransen M, Edmonds J. Reliability and validity of the EuroQol in patients with osteoarthritis of the knee. Rheumatology (Oxford, England). 1999;38(9):807-13.

35. Rolfson O, Bohm E, Franklin P, Lyman S, Denissen G, Dawson J, et al. Patient-reported outcome measures in arthroplasty registries Report of the Patient-Reported Outcome Measures Working Group of the International Society of Arthroplasty Registries Part II. Recommendations for selection, administration, and analysis. Acta Orthop. 2016;87 Suppl 1:9-23.

36. EuroQol Research Foundation. EQ-5D-5L User Guide: EuroQol Research Foundation 2019 [cited 202111 November]. Available from: https://euroqol.org/publications/user-guides.

37. Conner-Spady BL, Marshall DA, Bohm E, Dunbar MJ, Loucks L, Al Khudairy A, et al. Reliability and validity of the EQ5D-5L compared to the EQ-5D-3L in patients with osteoarthritis referred for hip and knee replacement. Qual Life Res. 2015;24(7):1775-84.

38. Lazarus RS. Patterns of adjustment. New York: McGraw-Hill; 1976.

39. Roost M, Zielinski A, Petersson C, Strandberg EL. Reliability and applicability of the Patient Enablement Instrument (PEI) in a Swedish general practice setting. BMC Fam Pract. 2015;16:31.

40. Enthoven P, Peolsson A, Ludvigsson ML, Wibault J, Peterson G, Oberg B. Validity, internal consistency and self-rated change of the patient enablement instrument in patients with chronic musculoskeletal pain. J Rehabil Med.

2019;51(8):587-97.

41. Greenhalgh T, Hinton L, Finlay T, Macfarlane A, Fahy N, Clyde B, et al. Frameworks for supporting patient and public involvement in research: Systematic review and co-design pilot. Health expectations : an international journal of public participation in health care and health policy. 2019;22(4):785-801.

42. Jones J, Cowe M, Marks S, McAllister T, Mendoza A, Ponniah C, et al. Reporting on patient and public involvement (PPI) in research publications: using the GRIPP2 checklists with lay co-researchers. Res Involv Engagem. 2021;7(1):52.

43. Cohen J. Statistical Power Analysis for the Behavioral Sciences. 2 ed. Mahwah: Lawrence Erlbaum Associates; 1988.

44. Jakobsen JC, Gluud C, Wetterslev J, Winkel P. When and how should multiple imputation be used for handling missing data in randomised clinical trials - a practical guide with flowcharts. BMC Med Res Methodol. 2017;17(1):162.

45. Sturesdotter Åkesson K, Beckman A, Stigmar K, Sundén A, Ekvall Hansson E. Physical activity and health-related quality of life in men and women with hip and/or knee osteoarthritis before and after a supported self-management programme - a prospective observational study. Disabil Rehabil. 2021:1-9.

46. Saarni SI, Harkanen T, Sintonen H, Suvisaari J, Koskinen S, Aromaa A, et al.The impact of 29 chronic conditions on health-related quality of life: a general population survey in Finland using 15D and EQ-5D. Qual Life Res. 2006;15(8):1403-14.

47. Burstrom K, Johannesson M, Diderichsen F. Health-related quality of life by disease and socio-economic group in the general population in Sweden. Health policy (Amsterdam, Netherlands). 2001;55(1):51-69.

48. Burstrom K, Johannesson M, Diderichsen F. Swedish population health-related quality of life results using the EQ-5D. Qual Life Res. 2001;10(7):621-35.

49. Tolvanen E, Koskela TH, Kosunen E. Comparison of the Patient Enablement Instrument (PEI) with two single-item measures among Finnish Health care centre patients. BMC health services research. 2019;19(1):376.

50. Bedford LE, Yeung MHY, Au CH, Tse ETY, Yim WY, Yu EYT, et al. The validity, reliability, sensitivity and responsiveness of a modified Patient Enablement Instrument (PEI-2) as a tool for serial measurements of health enablement. Fam Pract. 2020. 
51. Gustafsson K, Kvist J, Eriksson M, Dahlberg LE, Rolfson O. Socioeconomic status of patients in a Swedish national self-management program for osteoarthritis compared with the general population-a descriptive observational study. BMC Musculoskelet Disord. 2020;21(1):10.

52. Sturesdotter Åkesson K, Sundén A, Hansson EE, Stigmar K. Physiotherapists' experiences of osteoarthritis guidelines in primary health care - an interview study. BMC Fam Pract. 2021;22(1):259.

53. Gustafsson K, Kvist J, Eriksson M, Dell'Isola A, Zhou C, Dahlberg LE, et al. Health status of individuals referred to firstline intervention for hip and knee osteoarthritis compared with the general population: an observational registerbased study. BMJ open. 2021;11(9):e049476.

54. Bull LM, Lunt M, Martin GP, Hyrich K, Sergeant JC. Harnessing repeated measurements of predictor variables for clinical risk prediction: a review of existing methods. Diagn Progn Res. 2020;4:9.

\section{Figures}

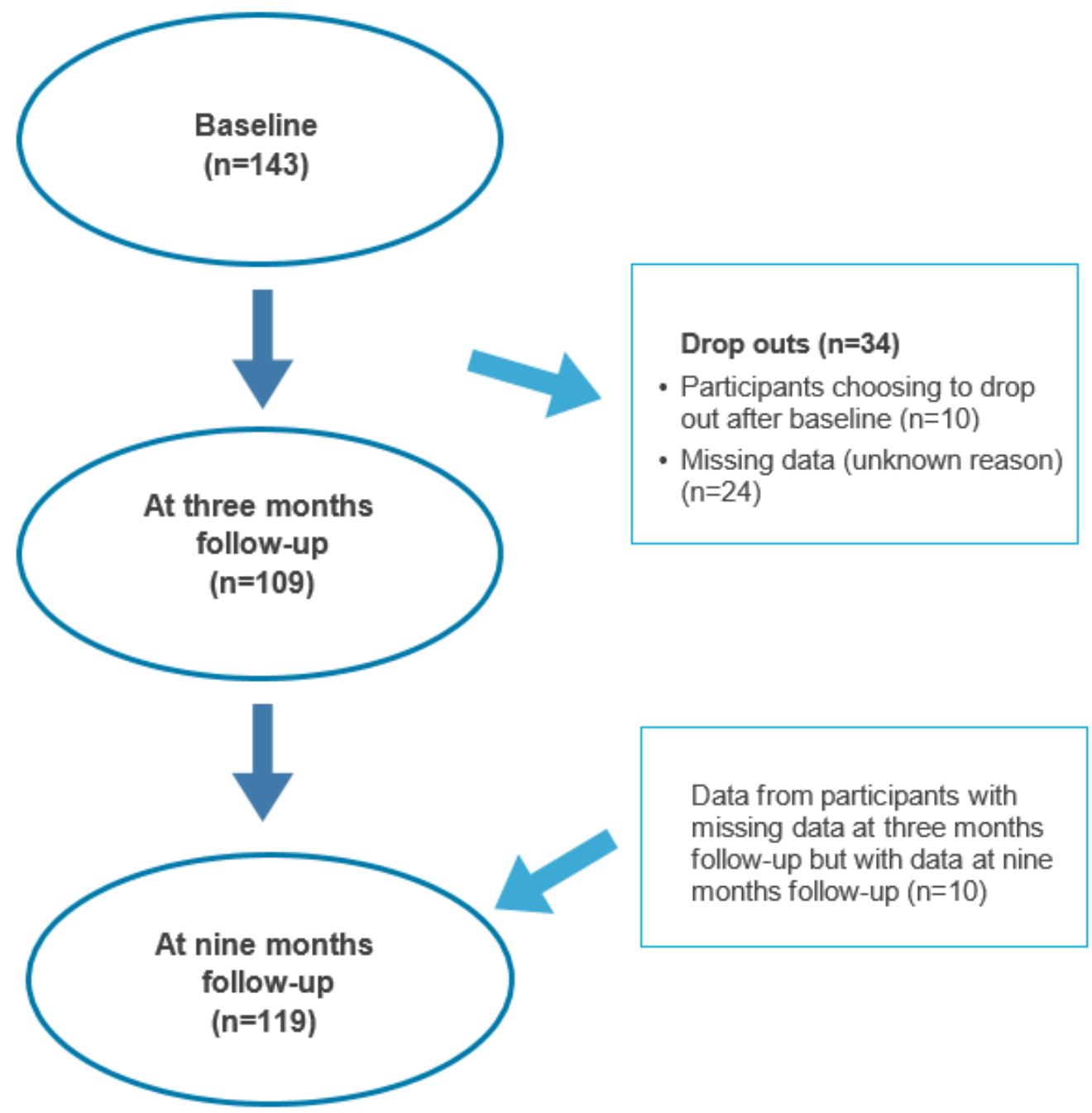

Figure 1

Flowchart for the data collection for analysis in the study.

\section{Supplementary Files}


This is a list of supplementary files associated with this preprint. Click to download.

- GRIPP2.docx 